\title{
Antártida. \\ La vida en el límite. Las expediciones Bentart
}

\author{
Óscar García Álvarez, Julio Parapar Vegas y \\ Ana Ramos Martos (coordinadores). 2011 \\ Hércules de Ediciones, Consejo Superior de Investigaciones Científicas, Coruña, 326 pp. más DVD
}

Antártida es un libro de divulgación majestuoso que sintetiza 20 años de investigación española en el bentos antártico. La obra resulta del esfuerzo de 48 autores vinculados a 18 centros de investigación y otras organizaciones gubernamentales. El contenido se reparte en siete capítulos: 'El mar antártico' (31 pp.), 'La exploración antártica' ( 25 pp.), 'Los proyectos Bentart 20 años de investigación en la Antártida' (41pp.), 'El trabajo a bordo' (23 pp.), 'Experiencias en acuarios' (21 pp.), 'El trabajo en tierra' (29 pp.), y 'El bentos antártico' (137 pp.). Cada capítulo consta de un autor principal y varios colaboradores que elaboraron síntesis variadas de la información existente. Las fotografías son de excelente calidad y la redacción es depurada, lo que contribuye a leerlo con amenidad y deleite.

El mar antártico, primer capítulo, es una caracterización geográfica y oceanográfica de la Antártida. Contiene ilustraciones muy bien acabadas y la información es de primera. La exploración antártica resume la historia y presenta detalles interesantes sobre el descubrimiento del continente y sobre varias expediciones en la región. Los autores destacan el arribo a la isla Livingston de los náufragos del navío español San Telmo, que en 1818 trasladaba más de 660 personas (naufragio en $1819^{1}$ ), en una época en que se perseguían los grupos de focas de isla en isla simultáneamente con

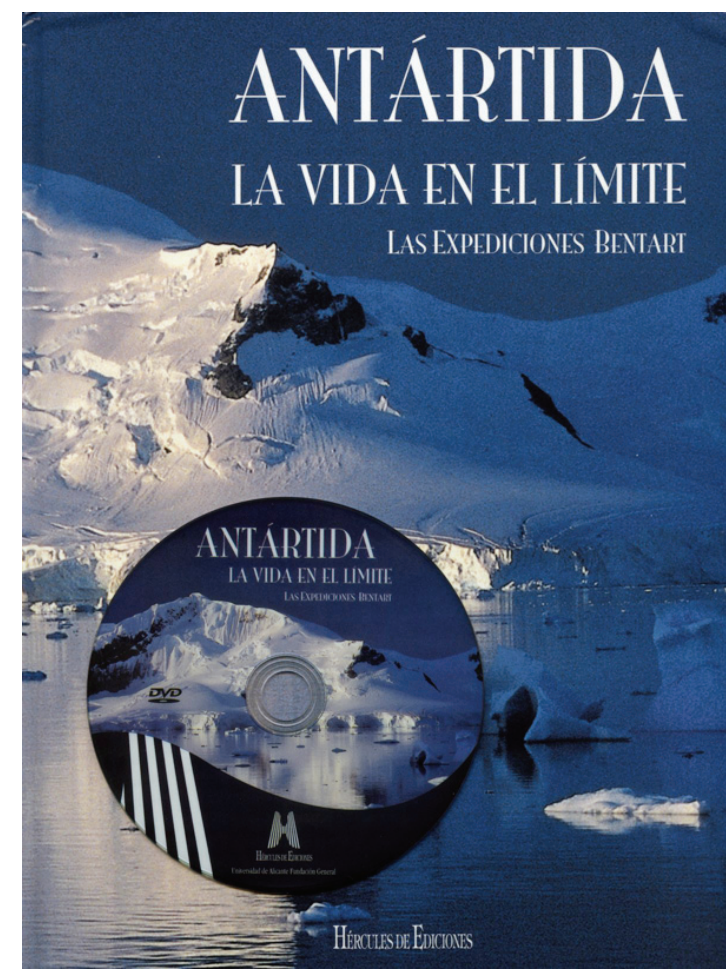
la activa caza de ballenas en el mar. Las expediciones científicas fueron impulsadas especialmente después del Congreso Internacional de Oceanografía y al empezar el siglo pasado se realizaron cuatro grandes exploraciones. No obstante, científicos españoles empezarían a participar marginalmente hacia fines de 1950, realizando la primera expedición marítima a principios de 1980, participando 23 personas. En 1986, realizaron una expedición que los autores consideran como el arranque de sus actividades: la campaña Antártida-8611. Por supuesto, la participación marginal quedó en el pasado porque actualmente España tiene dos estaciones y un buque construido ex profeso para la investigación antártica, el Hespérides.

El tercer capítulo reseña el desarrollo particular de las expediciones. Escrito por Ana Ramos, quien junto a Enrique MacPherson se reconocen como los promotores originales del estudio del bentos para la expedición Antártida-8611. Sus afanes cristalizaron en 390 muestras de sedimentos y 345 arrastres, algo que nunca antes se había realizado. Para el tratamiento e identificación de las muestras, se reconoce el respaldo de Patrick Arnaud y se realza que ahora participan 43 académicos de 18 centros de investigación. Entre los principales hitos de investigación, se indica que se han descrito unas 60 especies entre las más de 900 que han reportado. Sin embargo, el total hallado palidece ante las 5,200 especies estimadas (Gray 2001), aunque los registros superan las 8,200 especies (Griffiths 2010). Este porcentaje bajo de descubrimientos contrasta con las estimaciones o hallazgos basados en métodos moleculares, por lo que se puede anticipar un cambio drástico en las proporciones una vez que se terminen las revisiones o se incorporen métodos moleculares al estudio de la fauna. El panorama indica que falta mucho por hacer en todos los mares, incluyendo al Antártico.

${ }^{1}$ http://es.wikipedia.org/wiki/San_Telmo_(1788) 
Los siguientes tres capítulos describen las actividades a bordo del Hespérides, tanto para generar y procesar las muestras como para hacer observaciones en acuarios, y las correspondientes en tierra, una vez que los materiales han llegado a los laboratorios. La explicación del trabajo taxonómico enfatiza los problemas para la identificación pero aunque pueda parecer poco relevante, se omite mencionar la necesidad de realizar revisiones o monografías y no se enfatiza el uso de métodos moleculares (Mahon et al. 2010, Havermans et al. 2011), aún cuando algunos de los autores del libro han aplicado esas técnicas en organismos antárticos (PeñaCantero et al. 2010).

El bentos antártico es el mayor capítulo del libro. El contenido tiene una introducción general y luego se separa como suprabentos, epibentos, endobentos e ictiofauna. Particularmente, las secciones de epi- y endobentos hacen referencia a grupos taxonómicos de organismos específicos. Dado que la identificación ha sido problemática 'de todos los invertebrados capturados en el fondo marino' (p. 282), se comenta sobre el uso de espectros biomasa-tamaño corporal para realizar análisis ecológicos en los plazos indicados por las agencias financiadoras. Aunque para el análisis de la biodiversidad, los estudios taxonómicos siempre son de suma importancia.

El libro cumple su cometido al mostrar el mundo fascinante del bentos antártico y las fotografías son tan impactantes como clara y accesible es la redacción. Algunos detalles a mejorar en una nueva versión sería: insertar los nombres de las personas participantes en las fotos grupales; insertar nombres científicos en las fotos de especies o grupos de ellas, e incluir las direcciones electrónicas de los participantes para facilitar la comunicación de los interesados con los autores. Para fines de investigación o para promover el estudio de las colecciones, sería positivo indicar los lugares en que se encuentra el material depositado y cuáles son las publicaciones realizadas hasta el momento.

El libro además incluye un documental dirigido por José Antonio Moya en formato DVD, con una duración de $47 \mathrm{~min}$, que reseña varios de los aspectos centrales de la obra. Es interesante resaltar el reconocimiento tácito a la Fuerza Aérea de Chile, en su colaboración internacional, ya que esta institución ha facilitado aviones y personal para el traslado de los investigadores hacia la Antártida, lugar que no es de fácil acceso. Por otro lado, hay tres aspectos mejorables para una futura edición de este material audiovisual: la mayoría de las secuencias que ilustran especies o grupos de especies pasan sin alguna explicación sobre el grupo taxonómico en cuestión; las secuencias de lavado de muestras del bentos dejan ver que se usó la manguera en alta presión, técnica que puede deteriorar el material biológico; por último no se indican fuentes complementarias de información, lo cual es una falla general del libro.

En suma, Antártida es una de las pocas obras publicadas en español sobre divulgación que resulta extraordinaria porque combina la riqueza de contenidos con fotografías de primera y que tiene un documental asociado de excelente calidad. Considero que debiera ser leída por cualquier interesado en los mares australes y que por los comentarios en algunos foros, tendrá mucho éxito en las ventas. Finalmente, los detalles y sugerencias mencionadas puedo considerarlas menores porque la obra apunta más al terreno divulgativo por lo que los participantes deben ser congratulados por tan magníficos resultados.

\section{LITERATURA CITADA}

Gray JS. 2001. Antarctic marine benthic biodiversity in a world-wide latitudinal context. Polar Biology 24: 633-641.

Griffiths HJ. 2010. Antarctic marine biodiversity - What do we know about the distribution of life in the Southern Ocean? PLoS ONE 5(8): e11683, 11 pp. < doi:10.1371/journal.pone.0011683>

Havermans C, ZT Nagy, G Sonet, C de Broyer \& P Martin. 2011. DNA barcoding reveals new insights into the diversity of Antarctic species of Orchomene sensu lato (Crustacea: Amphipoda: Lysianassoidea). Deep Sea Research II 58: 230-241.

Mahon AR, DJ Thornbill, JL Norenburg \& KM Halanych. 2010. DNA uncovers Antarctic nemertean biodiversity and exposes a decades-old case of asymmetric inventory. Polar Biology 33: 193-202.

Peña-Cantero A, V Sentandreu \& A Latorre. 2010. Phylogenetic relationships of the endemic Antarctic benthic hydroids (Cnidaria, Hydrozoa): what does the mitochondrial 16S rRNA tell us about it? Polar Biology 33: 41-57.

Sergio I. Salazar-Vallejo

El Colegio de la Frontera Sur, Chetumal, México ssalazar@ecosur.mx, savs551216@hotmail.com 